\title{
Electron Microscopic Observations of Benign Tumors in Oral Maxillo Facial Lesions
}

\author{
TERUO HIEDA \\ Department of Oral Surgery, Kurume University School of Medicine, \\ Kurume, 830 Japan
}

Received for publication August 5, 1985

\begin{abstract}
Summary: Electron microscopic examinations were made in 20 cases of benign tumor lesions developing in the human lip, buccal mucosa, palate, dorsal area of the tongue and gum. The following findings were obtained. 1) The lumens were observed in pleomorphic adenoma. Microvilli of the tumor cells occurred on the inner side of the luminal wall and the cell organelles were well-developed. 2) The luminal wall of a capillary hemangioma was composed of a single layer of endothelial cells and there were many erythrocytes in the lumen. 3) In the lipoma, a massive proliferation of round fat cells of various sizes had occurred. The nuclei were marginal and lipid droplets in the cytoplasm were almost homogeneous. 4) The cells of the fibroma were spindly or stellate. A well-developed Golgi apparatus and rough surfaced endoplasmic reticulum were observed in the cytoplasm. 5) The cells in the neurilenoma were arranged in a regular pattern, but the cell processes were intertwined and covered with the basement lamina. 6) In the leimyoma many actin filaments and dense-paches were observed in the cytoplasm. 7) The cells of the granular cell tumor were enlarged and the nuclei were small. The cytoplasm was filled with many round osmophilic granules. 8) Many Schwann cells and fibroblasts were observed in the neurofibroma and mature collageneous fibers were frequently observed in the stroma. 9) A proliferation of collageneous fibers, reticular fibers, capillaries and osteoid figures were observed in the epulis fibromatosa. 10) In the cavernous hemangioma the inner layer of the vascular wall had a sacciform structure composed of flat endothelium. Edematous structures were observed in the subendothelial area. On the basis of these findings, it can be concluded that transmission and scanning electron microscopic examination is helpful in the differential diagnosis of tumor lesions.
\end{abstract}

Key words: oral maxillo facial lesion - electron microscopy — benign tumors of oral tissue - differential diagnosis - oral surgery

\section{Introduction}

Various benign tumors can develop in the oral maxillo facial region as well as at other sites in the body. Tumors in the oral cavity are relatively easy to find by inspection, but tumors which develop inside the maxillary region or at the palatal region are often difficult to find.

The clinical symptoms are a little dif- ferent among various kinds of tumors. Generally, the tumor growth is slow and expansive to the surrounding tissues. The prognosis is considered to be favorable. It is not always, easy, however to identify the tumor because each type of lesion can have various clinical pathological features.

Scanning and transmission electron microscopy, as well as conventional microscopic methods were used to make a defi- 
nite diagnosis of the type of tumor lesion developing in the soft oral tissues. The electron microscopic properties of the tumor in the oral region may be helpful in the differential diagnosis.

\section{Materials and Methods}

Twenty patients with tumors in the oral maxillo facial region were treated. The diseases were diagnosed as tumors clinically and pathohistologically at the Department of Oral Surgery, Kurume University Hospital (Table 1).

The tumors were excised under local or general anesthesia and examined with a light microscope and an electron microscope.

The specimens for the light microscopic study were prepared according to the con- ventional method and then stained with hematoxilin-eosin, azan-Mallory, PAS, or van Gieson stain. Another portion of the tumor that was to be used for the electron microscopic study was washed with distilled water immediately after collection and sliced. For the scanning electron microscopic (SEM) study the tissues were fixed in a $2.5 \%$ glutaraldehyde $/ 0.1 \mathrm{M}$ cacodylate buffer ( $\mathrm{pH} \mathrm{7.2)} \mathrm{for} 2$ hours, washed in distilled water, postfixed with $2 \% \mathrm{OsO}_{4}$ solution buffer for $2 \mathrm{hrs}$ at $4{ }^{\circ} \mathrm{C}$, dehydrated in graded alcohol, substituted with isoamyl acetate and dried by the critical point method. Specimens were sputter-coated with gold and examined with an SEM (Nihon Densi J-SMT-20 and Hitachi HFS-2). Tissues used for the transmission electron microscopic (TEM) study were extirpated and immediately cut into small pieces in a $2.5 \%$ glutaraldehyde or $2 \%$ paraformalde-

TABLE 1

Speciemens and diagnosis in twenty cases

\begin{tabular}{cccll}
\hline Case No. & Age & Sex & \multicolumn{1}{c}{ Location } & \multicolumn{1}{c}{ Diagnosis } \\
\hline 1 & 16 & F & Right upper lip & Pleomorphic adenoma \\
2 & 59 & M & do & do \\
3 & 49 & M & Right lower lip & do \\
4 & 13 & M & do & Capillary hemangioma \\
5 & 71 & M & Left lower lip & do \\
6 & 1 & F & Right buccal & Lipoma \\
7 & 3 & F & Right buccal & do \\
8 & 31 & M & Left buccal & Fibroma \\
9 & 26 & F & Right hard palate & do \\
10 & 57 & M & Right hard palate & do \\
11 & 19 & F & Right hard-soft palate & Neurilenoma \\
12 & 19 & F & Right lateral tongue & Leiomyoma \\
13 & 20 & F & do & Granular cell tumor \\
14 & 45 & M & 1|1 palatal gum & Neurofibroma \\
15 & 7 day & F & a | a labial gum & Granular cell tumor \\
16 & 39 day & M & do & Epulis fibromatosa \\
17 & 57 & M & |34 labial gum & Lipoma \\
18 & 90 & M & |45 buccal gum & do \\
19 & 16 & F & do & Neurilenoma \\
20 & 21 & F & Left mandibular gingiva & Cavernous haemangioma \\
\hline
\end{tabular}


hyde/0.1 M cacodylate buffer ( $\mathrm{pH} 7,2)$, post fixed with $2 \% \mathrm{OsO}_{4}$, dehydrated in graded acetone and embedded in Epon 812. Thin sections were cut with a glass knife on a Porter-Blum MT-1 microtome and double stained with uranyl acetate and lead acetate, and examined with a TEM (Hitachi-Hu-12 As and H-500). Semithin sections, about 1-2 um thick, were stained with toluidine blue for light microscopy.

\section{Results}

\section{Pleomorphic adenomas. Case 1,2 and 3} (Fig. 1, 2).

The cut surface of tumor tissues appeared relatively rough. Under the scanning electron microscope. Formations with various sized lumens and funiform or lamellar structures were observed. The inner diameters of most lumens were in the range of 10-50 um. Some of the luminal walls had many microvilli or varruca structures. Other lumens were rimmed with cells having short microvilli, that were lined up in a pavementlike arrangement. The tissues surrounding these lumens were rich in connective tissue.

The transmission electron microscopic examination revealed that the tumor was composed of a funiform or lamellar arrangement and consisted of the cells which formed many glandular ducts. Basement lamina existed between tumor parenchyma and stroma. The tumor cells which formed glandular ducts had large, amounts of rough surfaced endoplasmic reticulum in some parts. There was, however, little difference in the development of the cell organelles among the tumor cells. In the intercellular junction tumor cells were formed through a junctional complex such as desmosomes and tight-junctions, suggesting that pleomorphic adenomas might arise from the epithelial tissue.

\section{Capillary hemangioma. Case 4 and 5} (Fig. 3, 4).

SEM examination revealed a tumor existed under the stratified squamous epithelium. The capillary vessels were surrounded by a thin layer of connective tissue and had a large cysticform shape. Many erythrocytes were observed in the lumen. The endothelial cells were thick and had various shapes. The nucleus ratio was large. Mesenchymal cells and collagenous fibers existed around the blood vessels.

With TEM examination, the endothelial cells appeared round or ellipsoid and the nucleus swelled into the lumen. The endothelial cells were in close contact with each other through tight junctions. Cells with remarkably developed cell organelles were observed to have pinocytotic vesicles, mitochondria, rough surfaced endoplasmic reticulum, and many filament bundles. Endothelial cell membranes on the luminal wall surface were relatively smooth, but the membranes close to the basal area were rough and covered with basement lamina. Pericytes, fibroblasts, and abundant collagen fibers were obseved over the outside of the basement membrane.

\section{Lipoma. Case 6, 7, 17 and 18 (Fig. 5,6).}

The tumor tissue was covered with thin fibrous connective tissue and filled with proliferating fat cells of various sizes (about 50-70 um in diameter), which were separated into lobular shapes by connective tissue. In the figure of the cut surface, some round or elliptical fat cells were vacuolar due to the loss of the entocyte and fat cells with massive entocytes had uniformly high electron density. Moreover, fine granules which were probably lipid droplets existed abundantly or sporadically in some fat cells.

With TEM examination, tumor cells were variable in form and size. The intra- 
cellular area was homogeneous and like mature fat cells. The nuclei were extremely close to the margin and had a ring-like structure. The cell organelles were poor. Collagenous fibers, mesenchymal cells and capillary vessels existed on the outer side of the tumor cells.

\section{Fibroma. Case 8, 9 and 10 (Fig. 7, 8).}

The tumor was covered with fibrous tissue. The tumor consisted of proliferating fibroblasts which had spindly, asteroid, flat, or stellate shapes with long processes. The nuclei of the tumor cells were round or elliptical. The distribution of chromatin was relatively even. Well-developed tubuliform rough surfaced endoplasmic reticulum and Golgi apparatus were observed in the cytoplasm. There were many mature collageneous fibers with a repetitive structure $(64 \mathrm{~nm})$ in the stroma.

\section{Neurilenoma. Case 11 and 19 (Fig. 9, 10).}

These tumor cells were in close contact with each other and had a regular parallel or lamellar arrangement. The nuclei of the tumor cells were slender and were parallel with the apsides of the tumor cell. A few tumor cells had nucleoli. The spindly tips of the tumor cells spread irregularly, like a web, but did not fuse with each other. These processes were bordered by the basement lamina. Mitochondria, short rough surfaced endoplasmic reticulum, and fine filaments were observed in the cyoplasm.

\section{Leiomyoma. Case 6 (Fig. 11, 12).}

With SEM examination, proliferation of many snaky or fascicular bundles of smooth muscle fibers were observed. Some of these cells were more than $10 \mathrm{um}$ in width and up to $100 \mathrm{um}$ in length. Close to these bundles of smooth muscle fibers, collagenous fibers were observed. The cut surface of the tumor was relatively smooth.

The bundles of smooth muscle fibers were several um in width and tens of um in length. Characteristically, the nuclei were ellipical, the cell organelles were poorly developed, the bundles of fine myofilaments (actin) were almost homogeneous and existed in parallel with the line of upside of the tumor cell, and densepaches occurred sporadically. Many pinocytotic vesicles were observed in the cytoplasmic membrane. The tumor cells were covered with a basement lamina.

\section{Granular cell tumor. Case 7 and 15} (Fig. 13, 14).

The tumor cells were large and the nuclei were small and were close to the margin. The cytoplasm was filled with beaded or multilocular granules of various sizes. The tumor cells were arranged in a funiform or honey-comb-like arrangement.

TEM examination also showed that the tumor cells were large and the nuclei were small and near the cell margin. The cytoplasm was filled with granules of various sizes which could be osmiophlic and formed various structures such as a laminar or a fine granule-like structure.

\section{Neurofibroma (multile). Case 8} (Fig. 15, 16).

The neurofibroma tissue consisted of Schwann cells, fibroblasts, unmyelimated and myelinated fibers, small blood vessels, and collageneous fiberswith a typical repetitive structure. The Schwann cells were, in general, round or elliptical and the nucleolar-cytoplasmic ratio was large. There were few cell organelles. Only free ribosomes and fine filaments were observed. A well-developed basement lamina existed around the tumor cells. Many fibroblasts of various shapes were observed between the tumor cells. Fibroblasts with long process-like structures dominated. Single nerve fibers existed in the interstices besides fibroblasts. They were primarily unmyelinated nerve fibers but a few were myelinated. 


\section{Epulis fibromatosa. Case 9 (Fig. 17, 18).}

This tumor mass was covered with stratified squamous epithelium. At the submucosa, a proliferation of collageneous fibers and reticular fibers, as well as many capillary vessels, and mesenchymal cells were observed. Moreover, formation of os teoid substance, as indicated by an area of high electron density at the center and a peripheral area with a low electron density, was observed close to the base of the tumor mass.

On the TEM examination, the agminated tumor cells were relatively large and spindly or stellate shaped. These pictures suggest a differentiation of the tumor cells to fibroblasts. The nuclei were generally large. In the cytoplasm many vacuoles, rough surfaced endoplasmic reticulum, Golgi apparatus, and free ribosomes were observed. A proliferation of reticular fibers was observed in the stroma.

\section{Cavernous hemangioma. Case 10}

(Fig. 19, 20).

On the SEM examination, irregular vascular cavities of various sizes with a cystic form were observed on the cut surface. Vascular endothelial cells were variable in number and size, but the vascular walls were usually thin and the cavities were rimmed with elliptical endothelial cells which were lined up in a pavement-like arrangement. Many endothelial cell microvilli prjected into the cavities. A proliferation of fibrous substances, including mainly collagenous fibers and reticular fibers, was observed in the stroma.

The TEM studies revealed that the vessels had a cystic structure. In general, the innermost layer of the blood vessels consisted of flat endothelial cells. There were few endothelial cell organelles. The endothelium was surrounded by a single layer or a few layers of smooth muscle cells. Within the subendothelial layer characteristics of edema were observed. The blood vessels were surrounded by a thick con- nective tissue and anhistic stroma.

\section{Discussion}

Recently scanning and transmission electron microscopy have been used in histological studies of various types of lesions in the oral maxillo facial region. A scanning electron microscope is useful for observing superficial and sectioned figures of lesions (Nagata, 1981; Ohgami, 1982), while a transmission electron microscope is used to observe fine structures of lesions. The number of case reports with electron microscopic, as well as clinical and pathohistological, findings have been gradually increasing (Fukuya et al. 1985; Henderson and papadimitriou, 1982; Hori et al. 1982; Jinnouchi, 1978; Kameyama et al. 1983; Kawano, 1975; Kimura et al. 1974; Kojimahara et al. 1981; Miller et al. 1977; Oda et al. 1958; Oota, 1964; Saitoh et al. 1984; Sobel and Marquet, 1982; Yamada et al. 1985). There have been few case reports of benign tumor lesions which were examined by both scanning and transmission electron microscopy (Hoshino et al. 1980; Inoue et al. 1978; Kumanomido, 1984; Okina et al. 1979; Shiromoto et al. 1983; Shiromoto et al. 1983; Wakae et al. 1985; Yoshimura et al. 1982).

With regard to clinical figures, all the tumors that were reported in this paper were circumscribed. Their shape was globular or oval. The surface was relatively smooth. The color of the mucosa was normal. The size was in the range of a bean to the end of an index-finger which suggests that surgery would be subitable as a treatment for the disease. Therefore, extirpation or excision was performed under local or general anesthesia in all the cases. The cases described were initially diagnosed clinically and patho-histologically; and then to confirm the diagnosis, more detailed examination was made using both scanning and transmission electron micro- 
scopy as well as light microscopy.

The SEM and TEM findings from these cases can be summarized as follows.

1) The proliferation of epithelial cells and the formation of various sized lumens were observed in the pleomorphic adenoma.

2) The luminal wall of a capillary hemangioma was composed of a single layer of endothelial cells and many erythrocytes were observed in the lumen.

3) A massive proliferation of various sized fat cells (about 50-70 um in diameter) was observed in the lipoma. The nuclei were almost all near the cell margin.

4) The tumor cells of the fibroma were spindly or stellate. Development of the Golgi apparatus and rough surfaced endoplasmic reticulum were observed in the cytoplasm.

5) The tumor cells in the neurilenoma were arranged in a lamellar pattern and the processes of the cells were considerably entangled. The cells were covered by the basement lamina.

6) The cells in the leiomyoma were arranged in a fascicular or rope-like pattern. Many filaments (actin) and dense-patches were observed in the cytoplasm.

7) The nuclei in the granular cell tumor were small and marginal. The cytoplasm was filled with many round osmophilic granules.

8) Many Schwann cells and fibroblasts were observed in the neurofibroma and mature collagen fibers were frequently observed in the stroma.

9) A proliferation of collagenous fibers and reticular fibers and the formation of osteoid tissue were observed in the epulis fibromatosa.

10) Vascular endothelial cells were observed in the cavernous hemangioma. Collagenous fibers were observed in the stroma.

It has been known that tumor or tumorlike lesions can display many changes when the juvenile cells of tumor tissue are converted into differentiated cells or when undifferentiated tumor cells are subjected to sudden physiological, morphological, and/ or biochemical changes.

To obtain information which may be helpul in the differential diagnosis of tumors, benign tumor lesions which had developed in the human oral maxillo facial region were examined with SEM and TEM to clarify the morphological characteristics of tumor tissues and the implications of the mother tissue on tumor development. Much information was obtained which helped determine the developmental origin of the tumors and which might be helpful in the differential diagnosis. A further study on more cases is necessary to apply this information to the differential diagnosis of the various kinds of tumor tissues in the oral maxillo facial region.

It has been concluded that benign tumor lesions never recur and the prognosis is good (Shiromoto et al. 1983; Ichikawa et al. 1985; Ikeda et al. 1984). In all the reported cases, the post-operative course of the disease was favorable and abnormal findings, such as recurrence, were not observed.

(These results were presentted at the 27 th Annual Session of the Japanese Society of Oral Surgeons, Osaka, 1982, at the 46 th Annual Session of the Japanese Society of Oral Surgeons, Kyushu District, Kagoshima, 1985, and at the 30 th Annual Session of the Japanese Society of Oral and Maxillofacial Surgeons, Tokyo, 1985)

Acknowledgments: The authors gratefully acknowledge Professors C. Sujaku and M. Murakami for their constant interest and guidance, and Associate Professor T. Kameyama for his kindness and helpful advice.

\section{References}

Fukuya, Y., Shigehara, T., Asada, K., Haraguchi, K., One, H., Onizuka, T., Yamana, H. and TACHIKAWA, T. (1985). A case of congenital epulis. Jap. J.P.R.S. 28, 230-237.

Henderson, D. W. and Papadimitriou, J. M. (1982). Ultrastuctural appearances of tumors - $\mathrm{a}$ di- 
agnostic atlas - . edn. 1, pp. 200. Edinburgh, London: Churchill Livingstone.

Hori, M., Aida, T., Suquki, A., Otsuka, K., Miyake, M., Yokokawa, T., Tanaka, H., Kudo, I., Komiyama, K. and Kusama, K. (1982). Schwannoma in the region of the left lower wisedom tooth: Report of a case. Jpn. J. Oral Surg. 28, 1914-1919.

Horie, N., Kusuhara, S., Tsuchiya, H., Matsumoto, Y., Fujiki, S. and Takebe, M. (1985). Morphological study on neurofibroma and electron microscopic observations of schwann cell comparative study with schwannoma. Nihon Univ. Dent. J. 59, 98-103.

Hoshino, T., Ichimura, K., Yano, J. and Nozue, M. (1980). Histological study of the cystic lesions in the head and neck. Otolaryngology, 52, 329-336.

Ichikawa, J., Kurachi, Y., Ito, S., Otsuka, K., Nagumo, M. and Yamaguchi, A. (1985). Three case of lipoma of the alveolar gingival region. Jpn. J. Oral. Maxillofac. Surg. 31, 29-35.

Ikeda, N., Hashimoto, O., Kurita, K., Sugiura, M., Oriya, S., Shiraki, Y., Natsume, N., Hara, Y., Kawai, T., Mizohata, M. and Kameyama, Y. (1984). Congenital epulis: Report of two cases. Jpn. J. Oral. Maxillofac. Surg. 30, 1319-1323.

Inoue, H., Okina, T., Takenaka, M., Morinaga, E., Kawahara, H., Miyagi, T., Kitagawa, H., Ka wahara, H. and Kitahara, Y. (1978). Scanning and transmission electron microscopic observation of a congenital epulis. Kurme Med. J. 25, 17-24.

Jinnouchi, S. (1978). Transmission electron microscopic study on capillary hemangioma. J. KUR. M. A. 41, 52-69.

Kameyama, Y., Mizohata, M., Takehana, S., Murata, H., Manabe, H. and Mukai, Y. (1983). Ultrastructuel of the congenital epulis. Virchows Arch. [Pathol. Anat], 401, 251-260.

Kawano, K. (1975). Transmission electron microscopic study of epulis. National Defense Med. J. 22, 317-333.

Kimura, M., Kamata, Y., Matsumoto, K. and TAKAYA, H. (1974). Electron microscopical study on the tumor of von Recklinghausen's neurofibromatosis. Acta Path. Jap. 24, 79-91.

Kojimahara, M., Yamazaki, K. and Ooneda, G. (1981). Ultrastructural study of hemangiomas. I. Capillary hemangioma of the skin. Acta Pathol. Jpn. 31, 105-115.

Kumanomido, W. (1984). Scanning and trans- mission electron microscopic study of pleomorphic adenomas developing in the human palate region. J. Kyushu Dent Soc. 38, 275296.

Miller, A.S., Leifer, C., Chen Sow-Yeh and HarwIck, R. D. (1977). Oral grnular-cell tumorsReport of twenty-five cases with electron microscopy. Oral Surg. 44, 227-237.

Nagata, M. (1981). Scanning electron microscopic study on various lesions of oral mucosa and oral cysts - with special reference to sur face morphology of epithelial cells - Igaku Kenkyu. 51, 1-23.

Oda, T., Yoshizawa, K., Nakamoto, T., Kubo, Y. and OKazaki, H. (1958). An electron-microscopic study on lipogenesis. Acta Med. Okayama. 12, 29-41.

OHGAMI, K. (1982). Scanning electron microscopic study on the surface ultrastructure of nomal and patholgic oral mucosa. Tsurumi Univ. Dent. J. 8, 137-166.

Okina, T., Inoue, H., Nakamura, M., Kimura, T., Hieda, T., Sakima, M., Yamanaka, T., Wakae, H. and Okita, S. (1979). Differential diagnosis of oral tumor tissue by means of scanning electron microscope (2) - Congenital benign tumor-. Fukukuoka Dent. Coll. Soc. J. 6, 13-22.

OKina, T.,Takenaka, M.,Yamashita, S.,Nakamura, M., Yoshimura, M., Futami, M., Jinnouchi, S., Inoue, H., Kameyama, M., Wakae, H., Nagae, M. and ҮАмамото. (1979). Differential diagnosis of oral tumor tissue by means of scanning electron microscope (3) - Three cases in children-. Fukuoka Dent. Coll. Soc. J. 6, 227-235.

Оота, K. (1964). Electron-microscopic study on peripheral nerve tumors. Shinkei sinpo. 8, 48-64.

Saitoh, M., Komori, T., Fujimura, N., Ono, T., Enomoto, S. and OKada, N. (1984). Multiple granular cell tumor of the tongue: Report of a case. Jan J. Oral Maxillofac. Surg. 30, 839-883.

Shiromoto, M., Okina, T., Hino, Y., Yakeishi, Y., Takigi, F., Higashiyama, T., Mori, T., Sato, K. and Үамамото, M. (1983). Observation on a case of fibroma by scanning and transmission electron microscopy. Kurume Med. J. 30, 149-156.

Shiromoto, M., Shiromoto, K., Kimura, T., TAKenaka, M., Kameyama, T. and Sujaku, C. (1983). A case of schwannoma of the mandiblar body. 
Japan. J. Oral Max. Fac. Surg. 29, 547-552. Sober, H. J. and Marquent, E. (1982). Usefulness of electron microscope in the diagnosis of tumors. Path. Res. Pract. 167, 22-44.

Wakae, H., Hashimoto, S., Honda, S., Kamogawa, T., Kobayashi, M. and Tomioka, T. (1985). A case of lipoma occured in the buccal wall - Ultrastructture and electron microprobe EDX analysis - . Jpn. J. Oral. Maxillofac. Surg. 31, 104-109.
Yamada, K., Fujita, Y., Sato, R., Moriya, T., Kawamura, H. and Hayashi, S. (1983). Solitary intraosseous neurofibrom of the mandible: Report of a case. Jap. J. Oral Max. Fac. Surg. 29, 553-556.

Yoshimura, M., Kameyama, T., Kawahara, F., Takenaka, M., Hieda, T., Sujaku, C. and TaniMURA, A. (1982). A case of schwannoma developed from the floor of the mouth. Japn. J. Oral Surg. 28, 1216-1219. 
Case 1: Lip, Pleomorphic adenoma

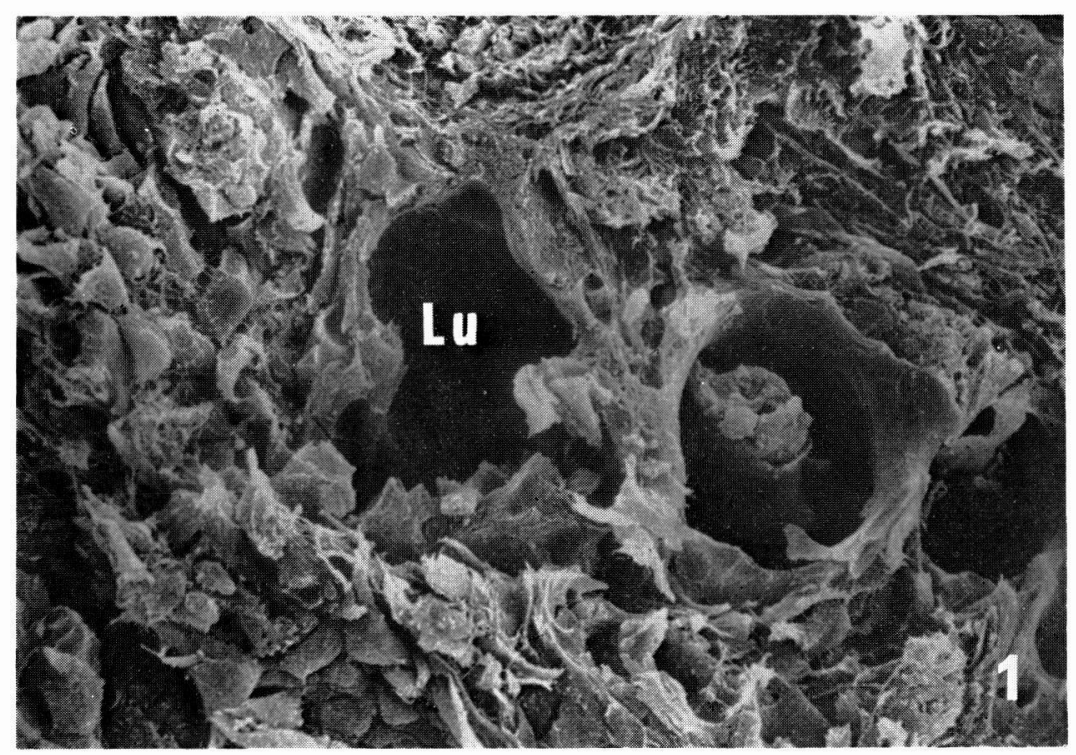

Fig. 1. The scanning electron micrograph of the tumor cell shows mostly a lumen with a surface that is smooth, and has short microvilli. (Lu) Lumen. $\times 200$.

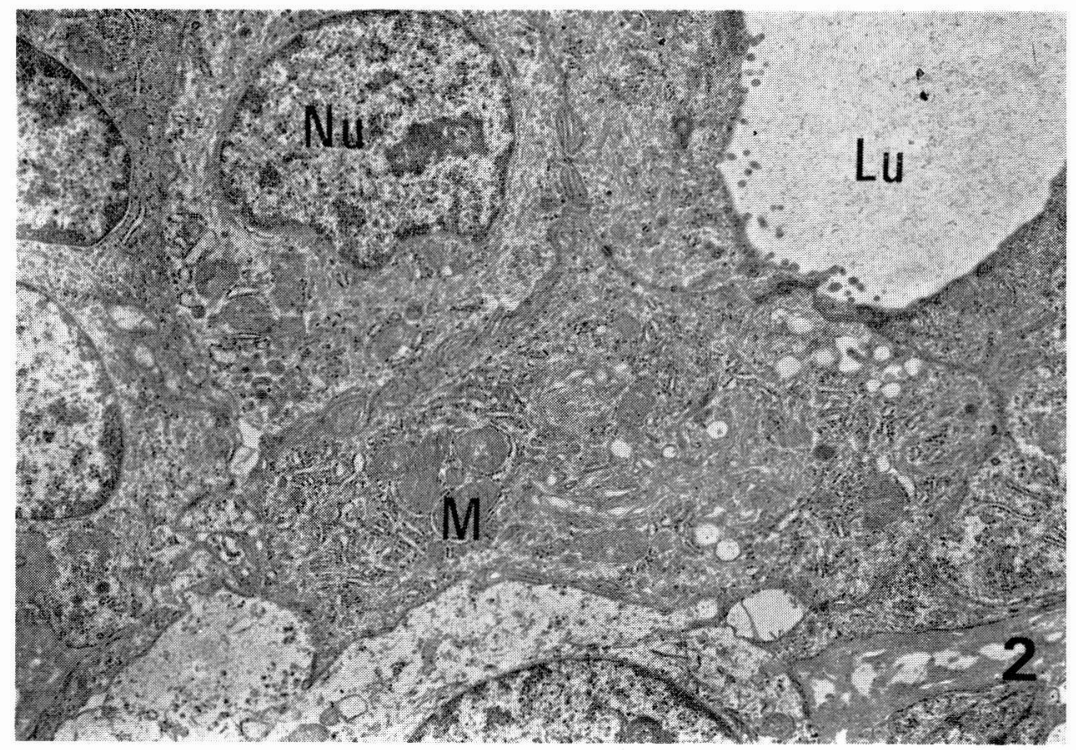

Fig. 2. Transmission electron micrograph; A wall of tumor cell in the cytoplasm is highly developed. (Nu) Nucleus. (M) Mitochondria. $\times 7,500$. 
Case 2: Lip, Capillary haemangioma

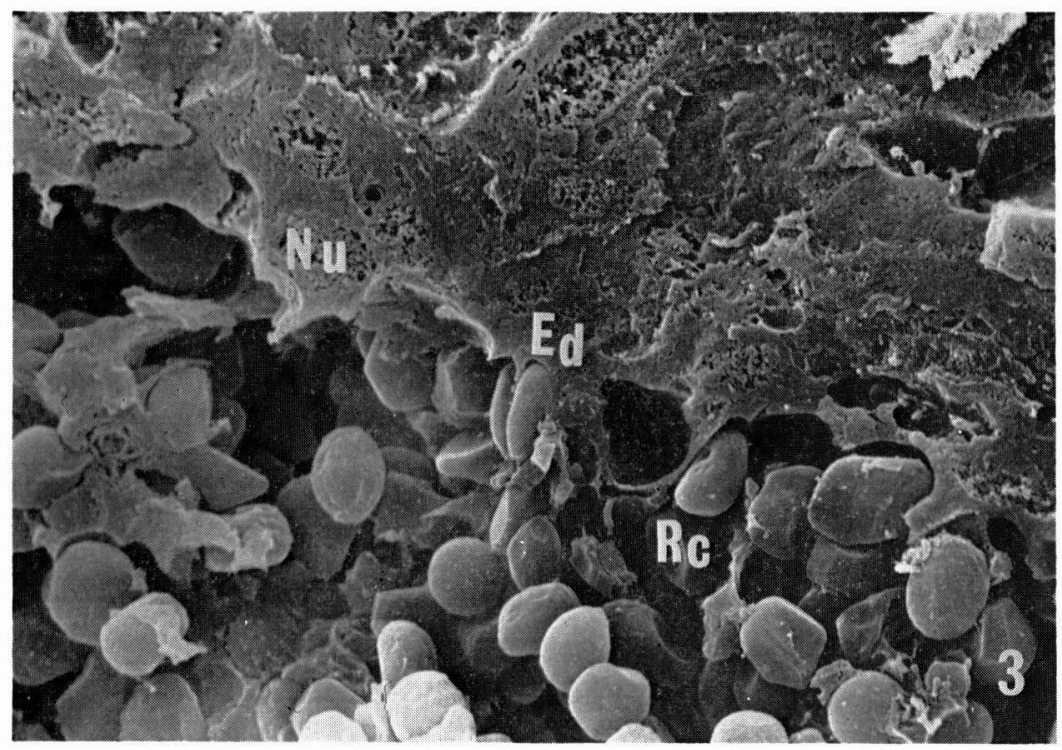

Fig. 3. SEM; An endothelial cell has a large nucleus, and numerous red cells are present in the lumen. (Ed) Endothelial cell. $(\mathrm{Nu})$ Nucleus. $(\mathrm{Rc})$ Red cell. $\times 2,700$.

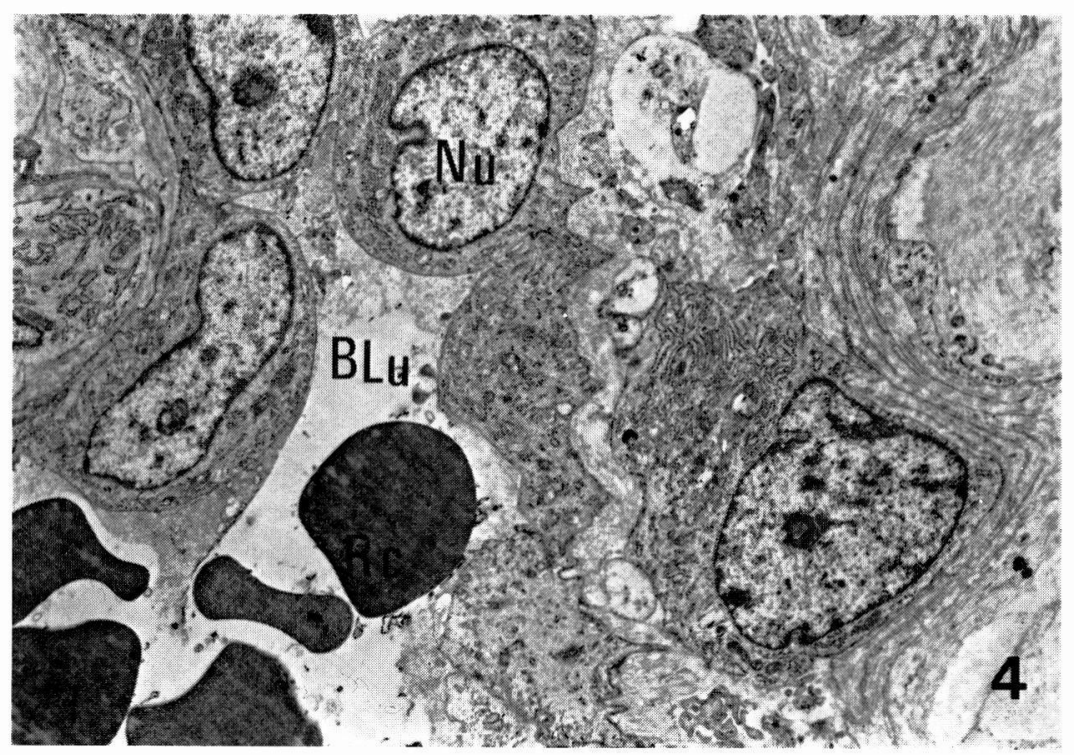

Fig. 4. TEM; The endothelial cells are covered by the continuous outer basement membrane. In some areas there are pericyte cells. $\quad(\mathrm{Nu})$ Nucleus. (Lu) Lumen. $\times 5,700$. 
Case 3: Buccal, Lipoma

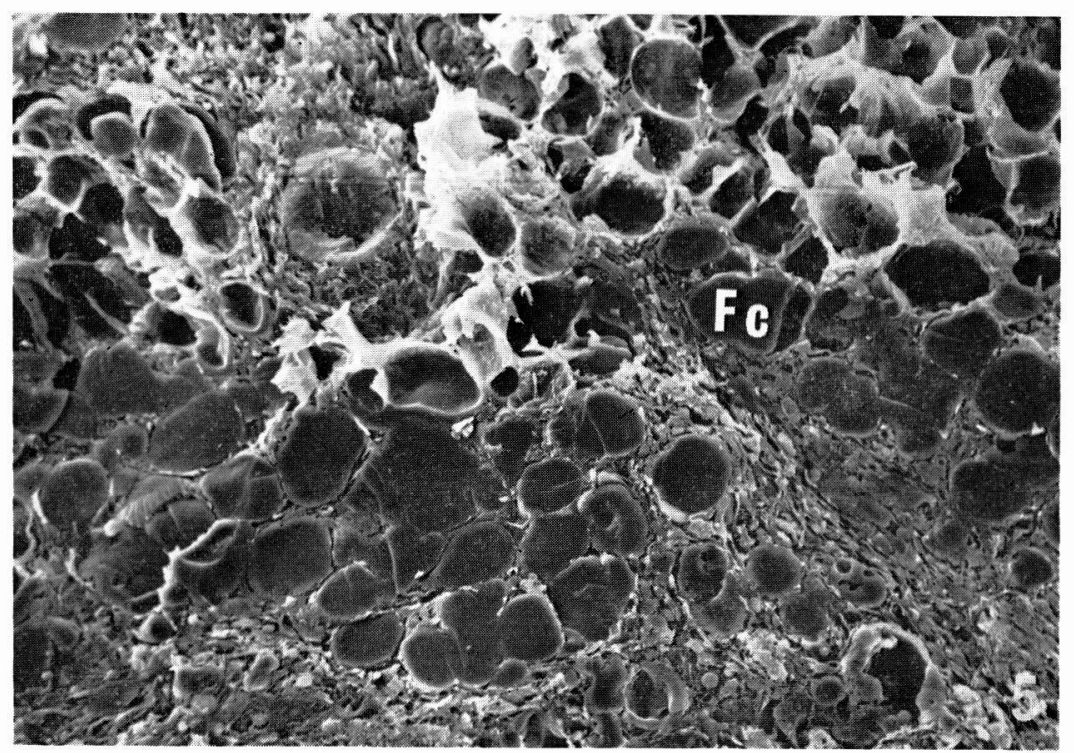

Fig. 5. SEM; There is a marked development of fat cells of various sizes. $\quad($ Fc) Fat cell. $\times 200$.

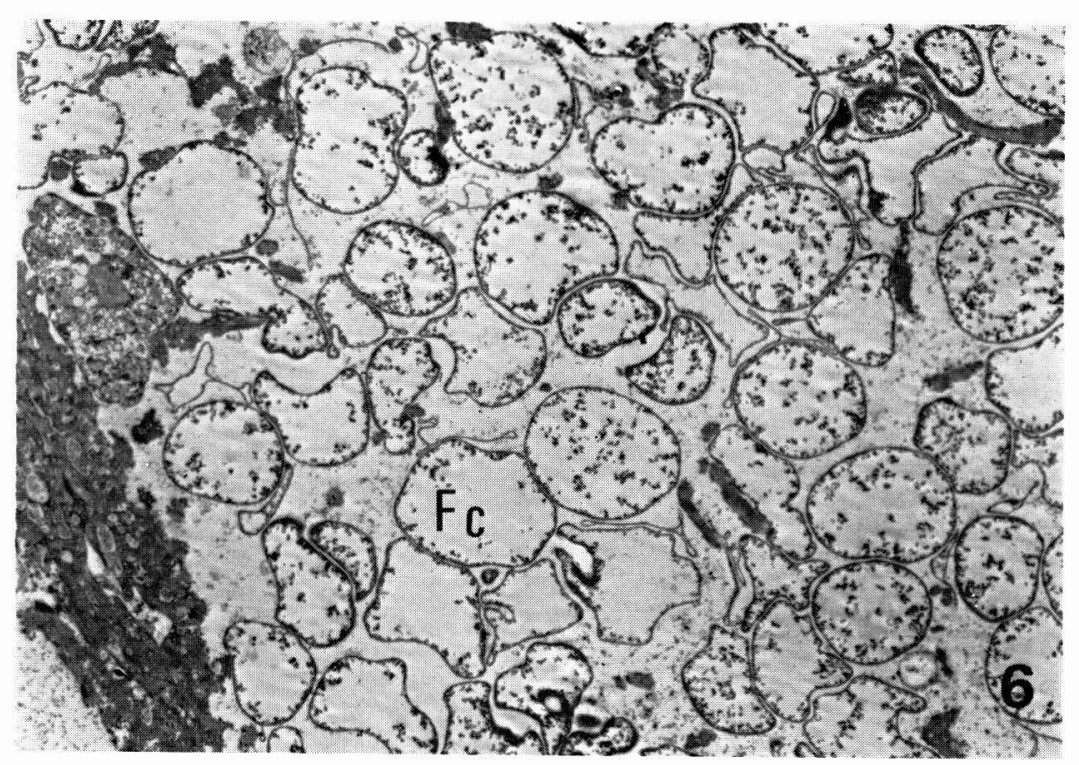

Fig. 6. TEM; A substance contained in the fat cells appeared to be flowing into the cytoplasm. The tumor cells are surrounded by collagenous fibers. (Fc) Fat cell. $\times 3,800$. 
Case 4: Palate, Fibroma
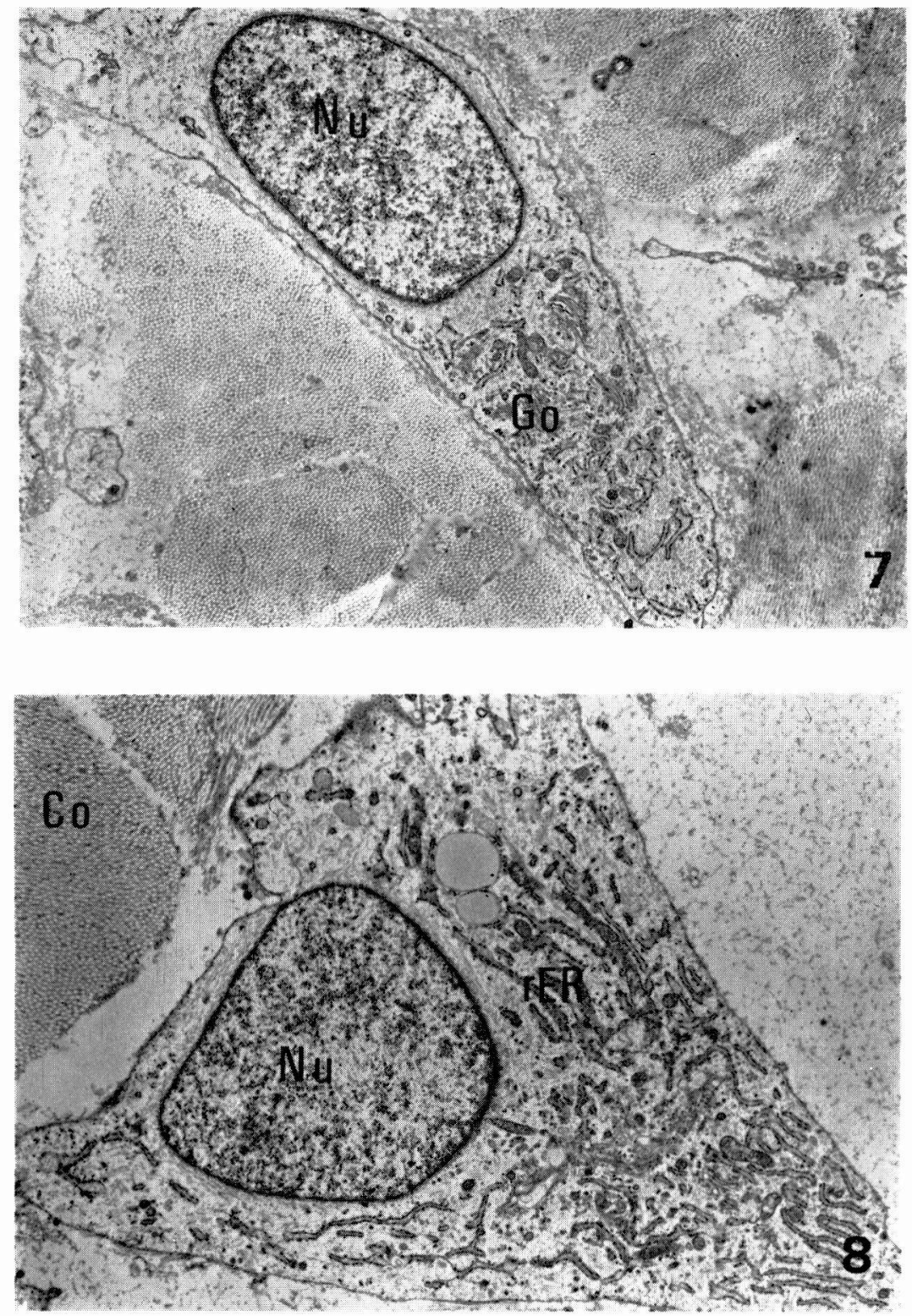

Figs. 7 and 8. Transmission electron micrograph: The tumor cell forms are spindle, astral and flat. In the cytoplasm development of the Golgi complex and rough surfaced endoplasmic reticulum are observed. (Nu) Nucleus. (Go) Golgi complex. (rER) roughsurfaced endoplasmic retiuclum. (Co) Collagen fiber. 7) $\times 7,600$. 8) $\times 6,600$. 
Case 5: Palate, Neurilenoma

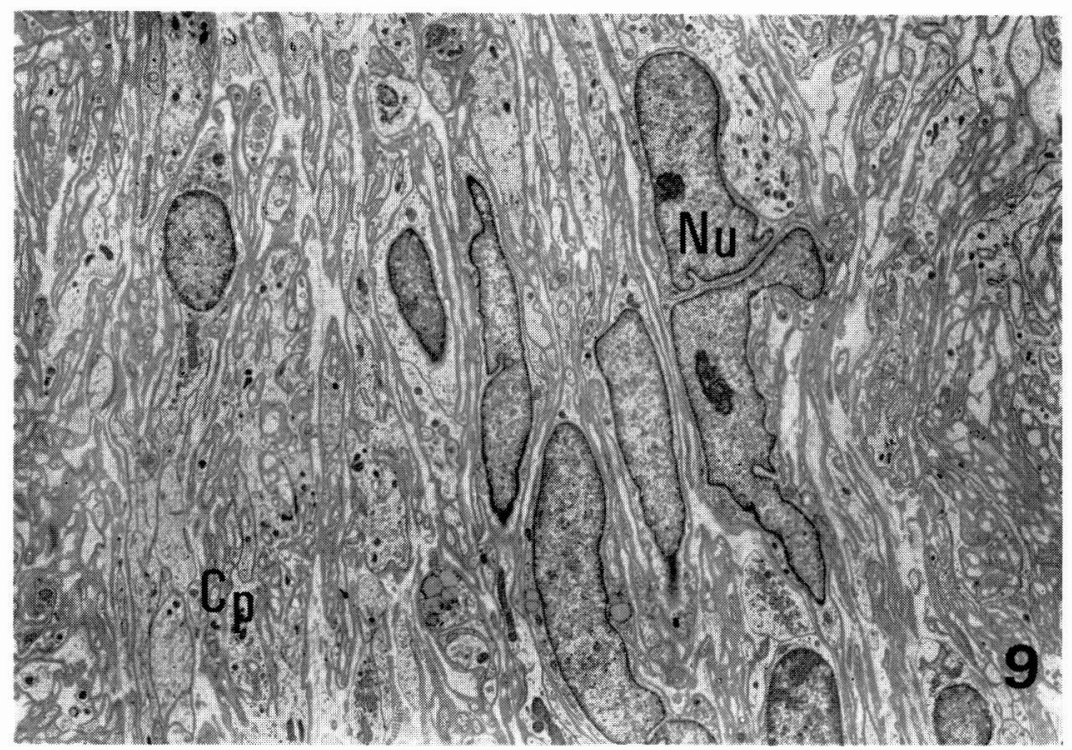

Fig. 9. Transmission electron micrograph: A sagittal section shows tumor cells aligned in a regular pattern and the nuclei are parallel. The cell processes are small with much intertwining. $(\mathrm{Nu})$ Nucleus. $\quad(\mathrm{Cp})$ Cell processes. $\times 3,800$.

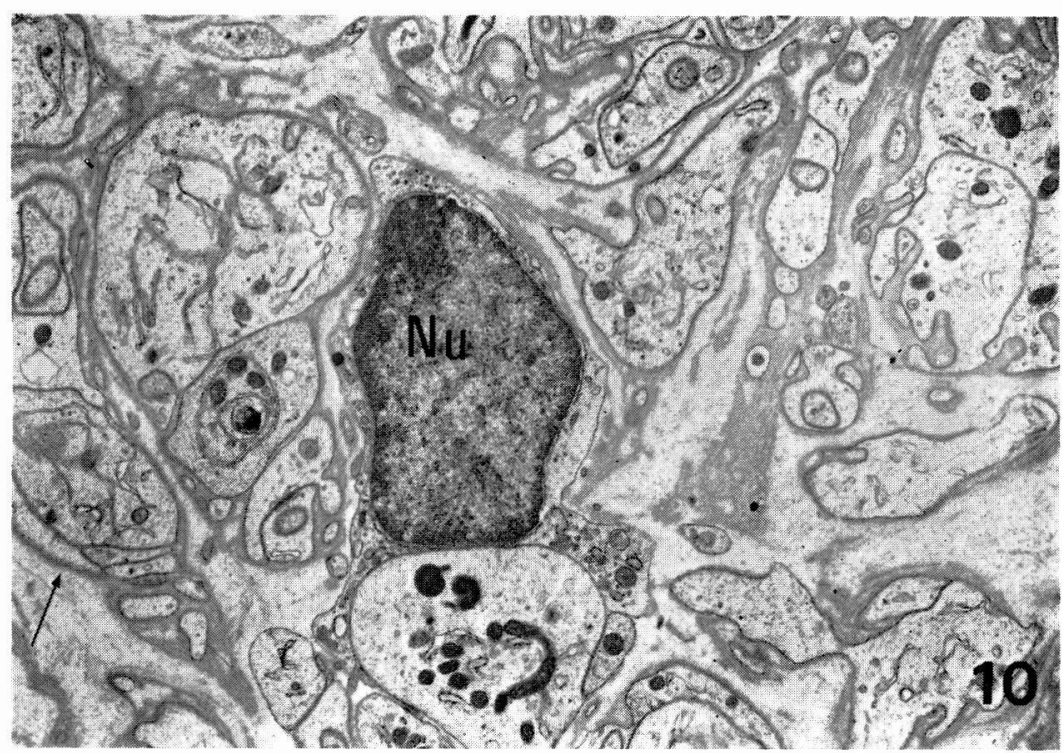

Fig. 10. TEM; This cross section shows that tumor cells of various sizes are covered by the lamina densa $(\longrightarrow)$. There is little cytoplasm. $\times 9,500$. 
Case 6: Tongue, Leiomyoma

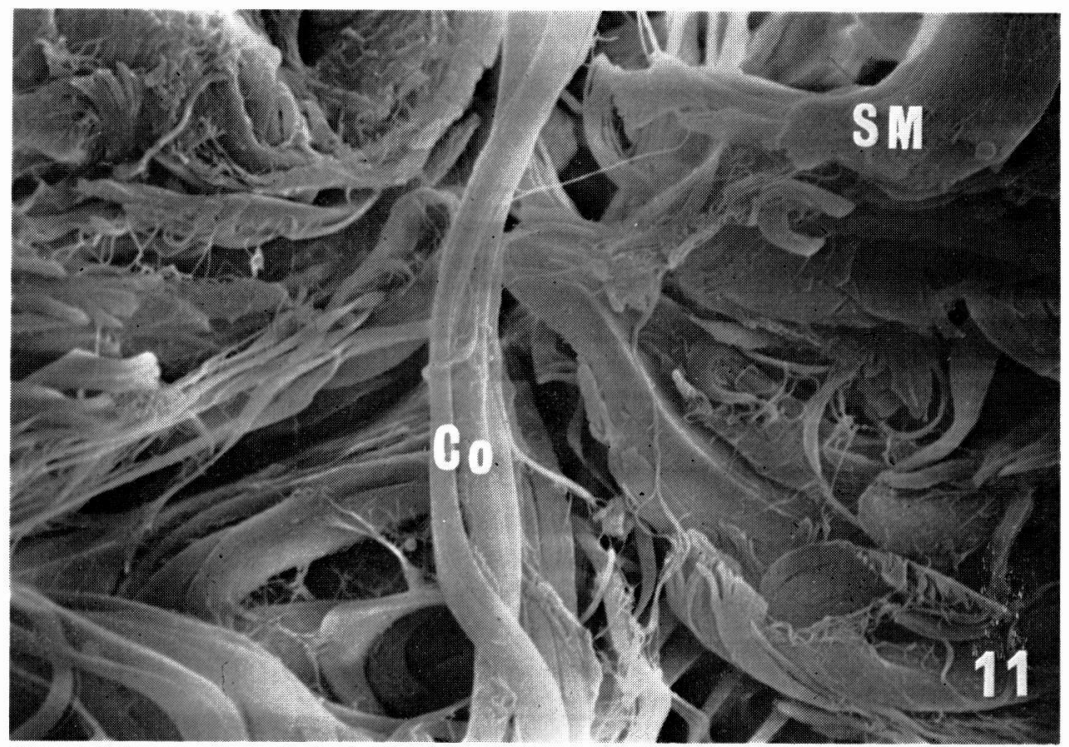

Fig. 11. Scanning electron micrograph: The development of smooth muscle is marked by a radial, arborescent or bundle shape. (SM) Smooth muscle. (Co) Collagen fiber. $\times 1,400$.

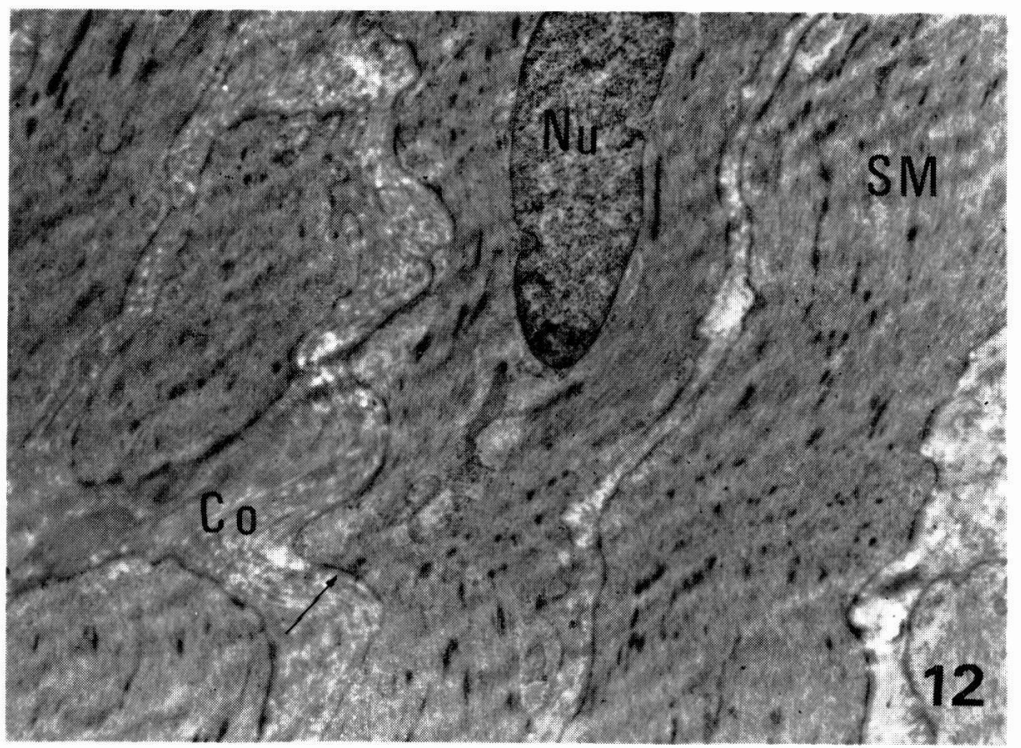

Fig. 12. TEM; Numerous actin filaments and dense patches occurred in the cytoplasm, but there are few elsewhere.

(SM) Smooth muscle. (Nu) Nucleus. Lamina densa $(\longrightarrow),(\mathrm{Co})$ Collagen fiber. $\times 6,000$. 
Case 7 : Tongue, Granular cell tumor.

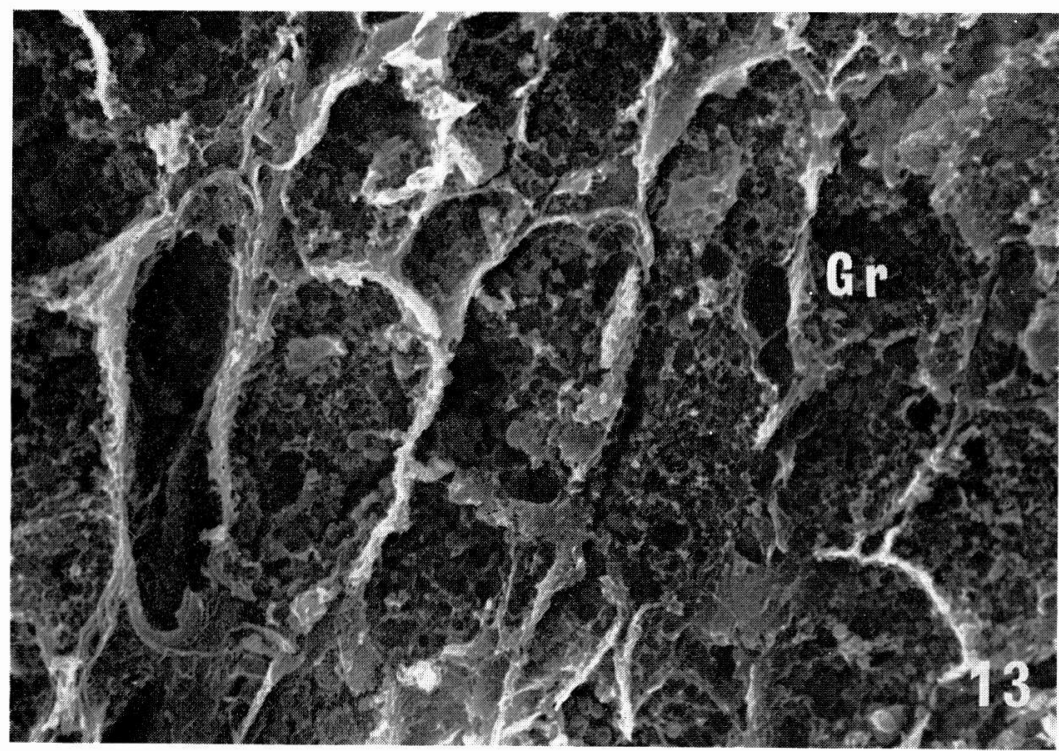

Fig. 13. SEM; The tumor cells had a honeycomb appearance and contained many granules in the cytoplasm. (Gr) Granule. $\times 2,000$.

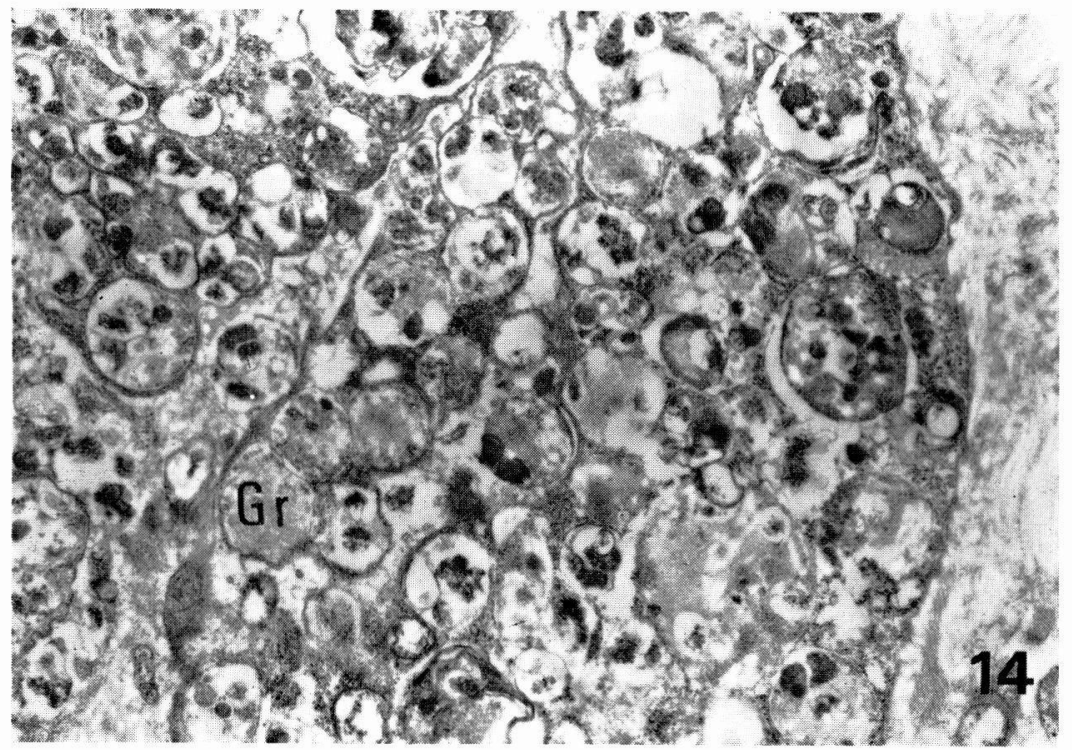

Fig. 14. TEM; There were many granular structures of various sizes, round and osmophilic. $(\mathrm{Gr})$ Granule. $\times 15,000$. 
Case 8: Gingiva, Neurofibroma.

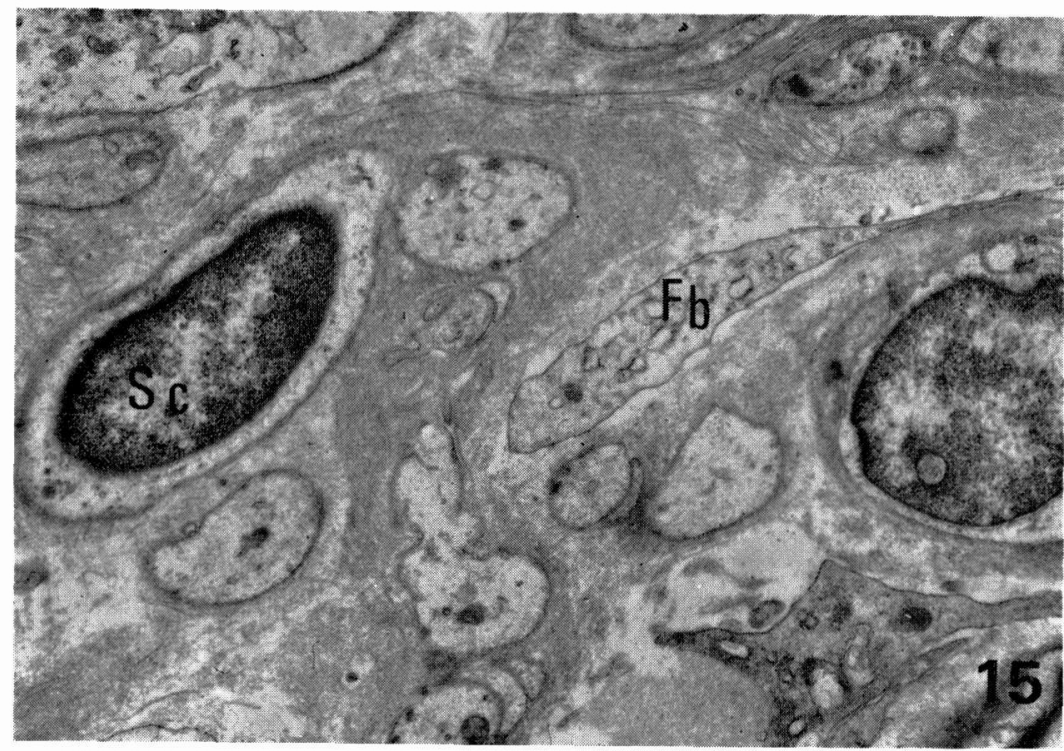

Fig. 15. TEM; Numerous Schwann cells and fibroblasts often occur and there is also an abundance of collagen fibers in the matrix. (Sc) Schwann cell. (Fb) Fibroblast. (Co) Collagen fiber. $\times 6,000$.

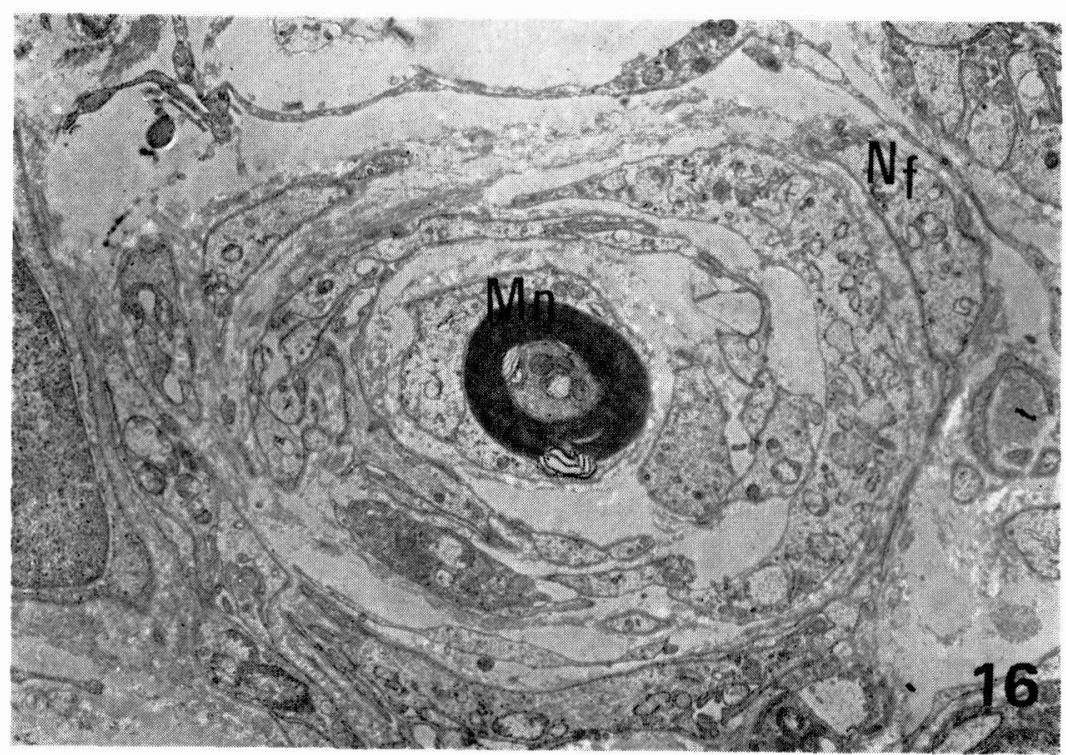

Fig. 16. TEM; The myelinated nervefibers are surrounded by the unmyelinated nerve fibers and associated Schwann cell.
(Mn) Myelinated fiber.
(Nf) Unmyelinated fiber.
$\times 5,500$. 
Case 9 : Gingiva, Epulis fibromatosa

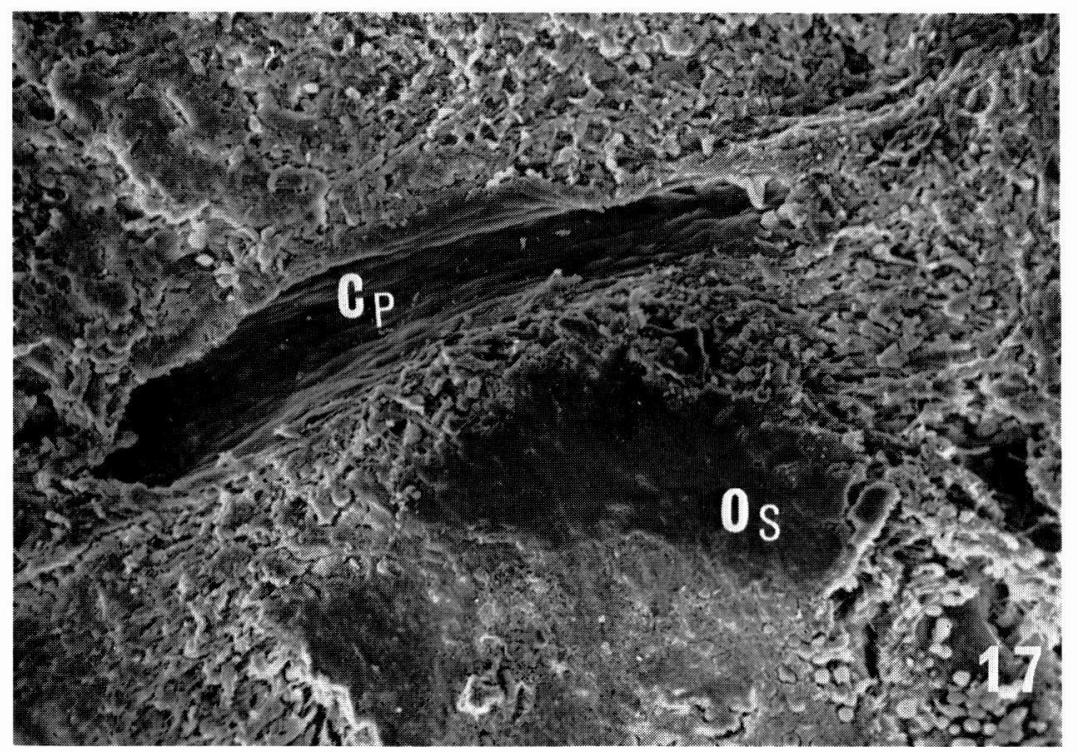

Fig. 17. SEM; Reticular fibers and collagen fibers are clustered in a lamina propria. Dilated capillaries and partially osseous formations can be observed. (Cp) Capillary. (Os) Osseous formation. $\times 300$.

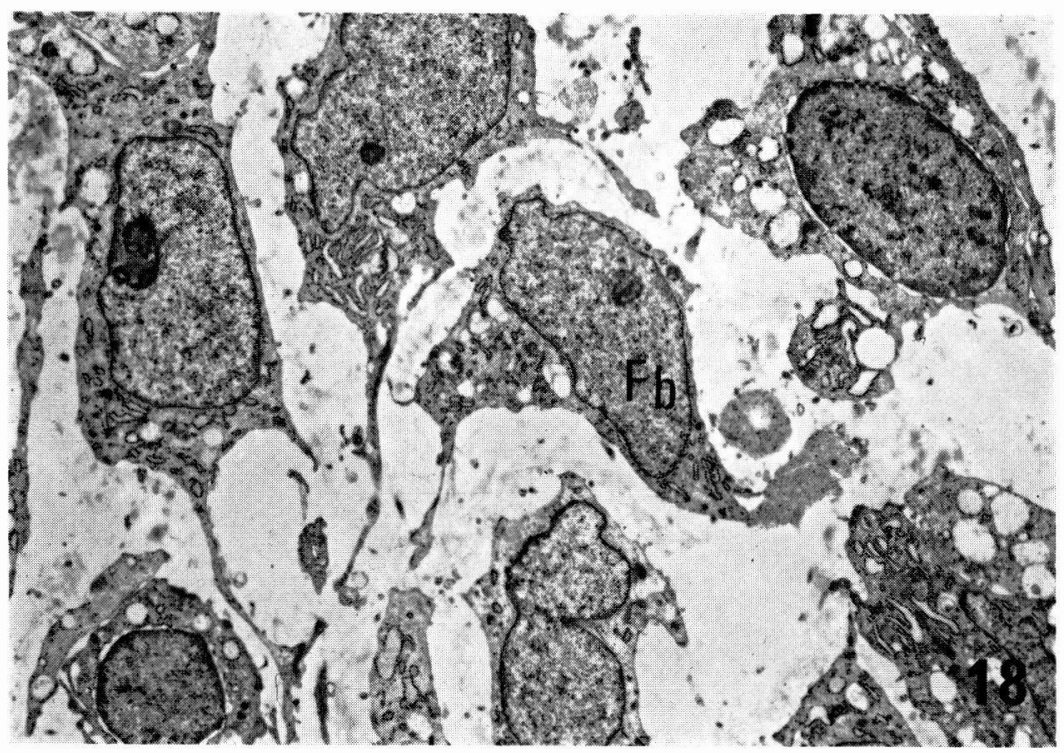

Fig. 18. TEM; Fusiform or stellated fibroblasts are clustered. (Fb) Fibroblast. $\times 7,000$. 
Case 10: Gingiva, Cavernous hemangioma.

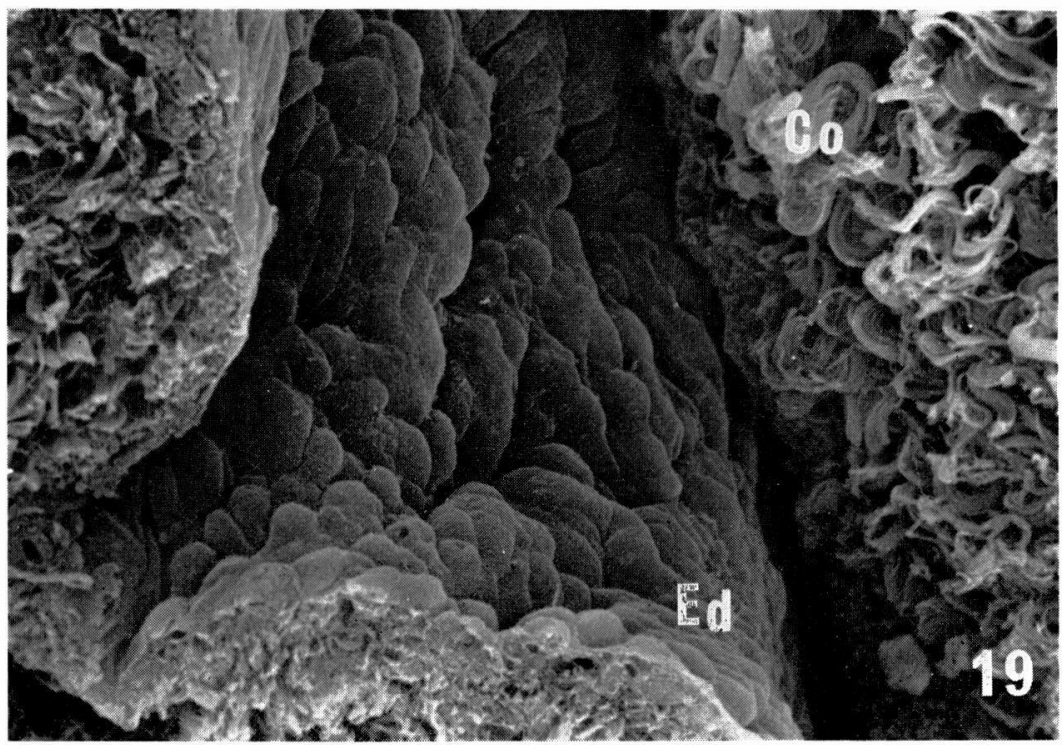

Fig. 19. SEM; The blood vessels are cystic shaped, the endothelial cell form is variable, and part of the nucleus protrudes as an oval shape. Mature collagen fibers can be recognized. (Ed) Endothelial cell. $(\mathrm{Co})$ Collagen fiber. $\quad \times 700$.

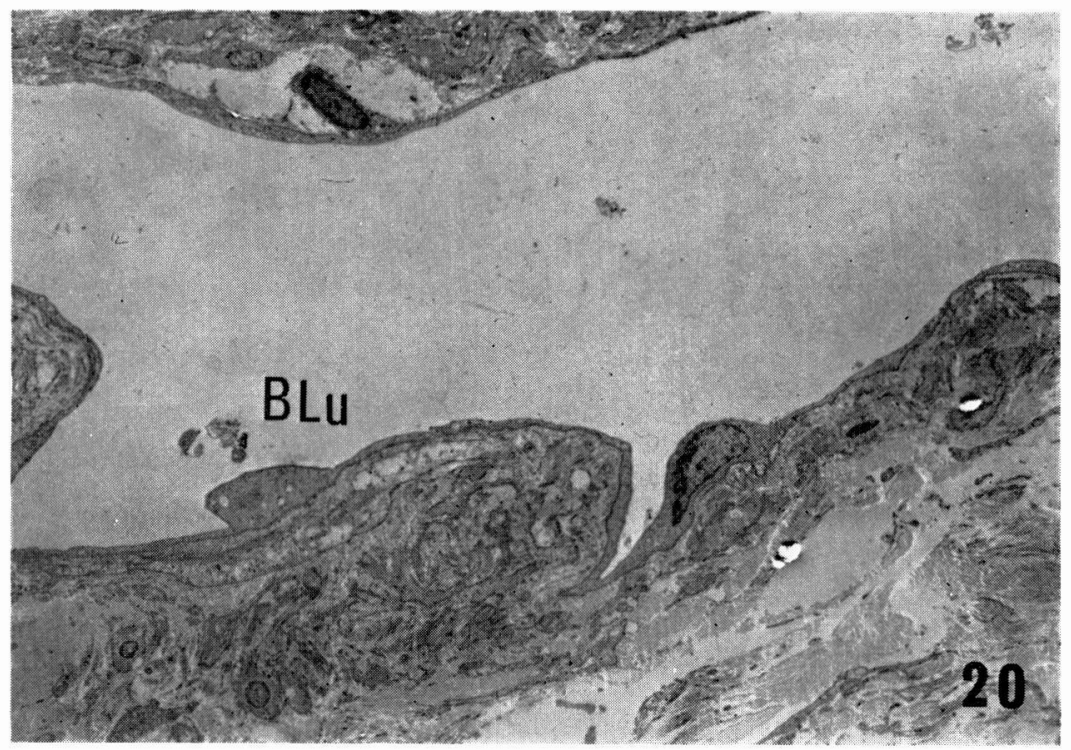

Fig. 20. TEM; The internal face of the blood vessel is generally flat. Outside of the endothelium edmatous features can be partially seen. $\quad(\mathrm{BLu})$ Lumen. $\times 1,600$. 